\title{
AVALIAÇÃO TEMPORAL DA UMIDADE DO SOLO COMO CONSEQÜÊNCIA DO TIPO E PERCENTAGEM DE COBERTURA VEGETAL
}

\author{
TEMPORAL VARIATION OF SOIL MOISTURE AS A RESULT \\ OF TYPE AND PERCENT OF SOIL COVER
}

\author{
Ben-Hur Costa de Campos ${ }^{1} \quad$ Dalvan José Reinert ${ }^{2}$ \\ Jackson Adriano Albuquerque ${ }^{1} \quad$ Renato Nicolodi ${ }^{3}$
}

\section{RESUMO}

No sistema de plantio direto a cobertura vegetal do solo favorece a infiltração de água da chuva e/ou irrigação e diminui as perdas por evaporação, mantendo a umidade em valores mais elevados em períodos de estiagem, principalmente, na camada superficial. Este trabalho foi desenvolvido de maio de 1991 a maio de 1992, em área do Departamento de Solos, no Campus da UFSM. O objetivo foi avaliar o efeito de diferentes tipos de coberturas vegetais sobre a umidade da camada superficial do solo, para a cultura do milho cultivada em sistema de plantio direto. Os tratamentos constaram das espécies de inverno: chicharo (Lathyrus sativus), tremoço (Lupinus angustifolius), ervilhaca (Vicia sativa), aveia preta (Avena strigosa) e pousio invernal, antecedendo a cultura do milho. A cobertura vegetal foi avaliada pelo método do ponto quadrado em intervalos regulares. A umidade gravimétrica do solo foi avaliada mensalmente, desde a implantação dos tratamentos até a colheita do milho. Houve variabilidade temporal da cobertura vegetal e umidade do solo. Os tratamen- tos que mais se destacaram na cobertura do solo foram aveia preta e chicharo, tendo esta reflexo direto no maior valor de umidade do solo. O tratamento em pousio invernal apresentou menor cobertura do solo e, conseqüentemente, menor umidade durante o período de agosto de 91 a maio de 92.

Palavras-chave: umidade do solo, variação temporal, cobertura do solo, plantio direto.

\section{SUMMARY}

Soil cover by crops and straw may improve water infiltration and reduce evaporation rate contributing to water conservation at top soil layer. This study was carried out at the experimental area of Soil Science Department, Santa Maria, RS, from May 1991 to May 1992. The objective was to evaluate the impact of winter cover crops on soil water conservation. After winter cover crops, maize was grown in no-tillage system. The cover crops used as treatments were: legumes (Lathyrus sativus,

\footnotetext{
'Engenheiro Agrônomo, Aluno do Curso de Pós-Graduação em Agronomia, da Universidade Federal de Santa Maria (UFSM) - $97119-900$ Santa Maria, RS.

${ }^{2}$ Engenheiro Agrônomo, Professor Titular, Departamento de Solos da UFSM - Pesquisador do CNPq, autor para correspondência.

${ }^{3}$ Acadêmico de Agronomia, Bolsista de Iniciação Científica - CNPq. 
Lupinus angustifolius and Vicia sativa) and oat (Avena strigosa). Fallow was used as the reference treatment. Soil water content was monthly measured. There was temporal variation of soil cover and moisture. They were closed related between each other. Oat conserved more water content along the studied period. Winter cover crops were significantly efficient in conserving water as compared to fallow treatment.

Key words: soil moisture, temporal variation, soil cover, no-tillage.

\section{INTRODUÇÃO}

Uma variação da umidade do solo, na camada superficial, tem sido observada quando diferentes tipos de cobertura vegetal são utilizadas. De uma maneira geral, a cobertura vegetal do solo favorece a infiltração da água da chuva e/ou irrigação e diminui as perdas por evaporação, mantendo a umidade em valores mais elevados, principalmente, na camada superficial.

Técnicas de cultivo do solo, com cobertura vegetais, assumem grande importância nas regiôes tropicais e subtropicais, onde a energia solar incidente é de grande intensidade. A cobertura vegetal dissipa, por reflexão, parte dessa energia, diminuindo as perdas de água por evaporação (BAVER et al., 1973).

Existe uma crescente conscientização quanto à eficiência dos resíduos agrícolas ou coberturas vegetais na reduçăo de perdas de água em terras cultivadas, não só sob a forma de vapor, mas também por escoamento superficial (BRADY, 1989). Segundo PRASAD \& POWER (1991), a redução da taxa de evaporação da água do solo, é uma das maiores vantagens da permanência de resíduos culturais na superfície do solo.

Preparos conservacionistas têm sido mencionados como uma alternativa para economizar tempo, combustivel, trabalho e incrementar a capacidade de suprimento da água do solo para as culturas. Eles contribuem para diminuição da erosão do solo e de problemas relacionados a poluição do ar e água (MUNAWAR et al., 1990).

Estudos feitos nos Estados Unidos demonstram que o armazenamento da precipitação durante o outono é maior quando resíduos são mantidos na superfície do solo do que quando incorporados (PRASAD \& POWER, 1991).

BLEVINS et al. (1973) encontraram maior produção de milho em solo sob plantio direto, do que em solo sob preparo convencional. Os autores explicaram esta diferença a maior disponibilidade de água, para as plantas, no plantio direto devido ao maior índice de cobertura do solo. Da mesma forma, MENDES (1982) concluiu que a cobertura morta do solo, foi responsável pelos maiores valores de umidade do solo em plantio direto, na profundidade de um a três centímetros.

O efeito da implantação de cobertura vegetal de diferentes leguminosas e gramíneas sobre a umidade do solo, tem sido ainda pouco investigada. No sistema de plantio direto, a cobertura vegetal usada tem sido, predominantemente, a aveia preta, havendo a necessidade do estudo de plantas de cobertura alternativas. A cobertura com leguminosas têm como vantagem a fixação biológica do nitrogênio atmosférico, porém, os resíduos deixados na superfície do solo são mais rapidamente decompostos em relação a cobertura com gramíneas.

Alterações na umidade do solo são dinâmicas, e ocorrem em curto e longo período de tempo, principalmente na camada superficial do solo. Alterações temporais estão associadas a fatores como manejo do solo e de culturas, tipo de cultura e fatores ambientais (KAY, 1990).

A adoção de sistemas de manejo do solo e das culturas, adequadamente conduzidas, proporcionam um aporte de material vegetal através dos residuos e plantas vivas que oferecem proteção à superfície do solo. Esta proteção é importante na conservação da umidade do solo, que terá influência direta na produtividade da cultura, principalmente, nos meses com déficit hídrico, os quais são muito comuns, nesta região, durante o ciclo do milho.

Considerando o acima exposto e a relevância da cultura do milho para a região, o presente trabalho avaliou o efeito de plantas de cobertura de inverno, incluindo leguminosas e gramíneas, antecedendo a cultura de milho em plantio direto, sobre a variação temporal da umidade do solo.

\section{MATERIAL E MÉTODOS}

Este trabalho foi desenvolvido de maio de 1991 a maio de 1992, em área pertencente ao Departamento de Solos, no campus da UFSM. O experimento foi instalado em solo Podzólico Vermelho-Amarelo, pertencente à unidade de mapeamento São Pedro (BRASIL, 1973). A análise do solo apresentou as seguintes caraterísticas: argila $=15 \% ; \mathrm{pH}$ em água $1: 1=5,4 ;$ indice $S M P=6,0 ; P$ (Mehlich) $=8,4 \mathrm{mg} / \mathrm{kg} ; \mathrm{K}$ trocável=108 mg/kg; Al trocável=0,37 me $/ 100 \mathrm{~g} ; \mathrm{Ca}+\mathrm{Mg}$ 
trocáveis=3,19 me $/ 100 \mathrm{~g}$ e matéria orgânica= 0,75 \%.

O delineamento experimental foi o de blocos ao acaso, em quatro repetiçð̃es. Cada parcela mediu $5 \times 5 \mathrm{~m}$.

Os tratamentos utilizados foram: chícharo (Lathyrus sativus L.), enilhaca (Vicia sativa L.), tremoço azul (Lupinus angustifolius L.), aveia preta (Avena strigosa Schieb) e pousio invernal.

$\mathrm{Na}$ instalaçăo do experimento, o solo foi preparado pelo sistema convencional com correção da acidez. No primeiro ano, as plantas de cobertura de inverno foram semeadas a lanço, sem adubação, e incorporadas através de uma gradagem. Nos anos subseqüentes, a implantação anual das plantas de cobertura de inverno foi feita da mesma maneira. Antecedendo o plantio do milho, em 24 de setembro de 1991, as mesmas foram manejadas através de uma gradagem, para provocar a interrupção de seu ciclo vegetativo, com mobilização mínima de solo. No tratamento pousio invernal foi aplicado dessecante.

O milho foi semeado no espaçamento de um metro entre linhas, perfazendo uma população aproximada a 45000 plantas/ha. A adubação com $P$ e $K$ foi a mesma em todos tratamentos de acordo com análise de solo.

Em cada parcela foram coletadas mensalmente, desde a semeadura das plantas de cobertura até a colheita do milho, duas subamostras de solo na profundidade de $0-5 \mathrm{~cm}$, com o auxílio de cilindro volumétrico, compondo uma amostra para análise da umidade do solo pelo método gravimétrico. As coletas foram feitas a partir de uma extremidade, de cada parcela, avançando para a outra, nas coletas subseqüentes.

As coberturas morta e vegetal viva foram avaliadas pelo método do ponto quadrado, semelhante ao usado por SPEDDIND \& LARGE (1957), em intervalos regulares.

Os resultados foram avaliados estatisticamente pela análise da variância e teste de comparação de médias para cada coleta, utilizando o pacote estatístico SAS.

\section{RESULTADOS E DISCUSSÃO}

Houve variação temporal da umidade do solo devido aos ciclos de umedecimento e secagem, conseqüente de eventos de chuva e estiagem (Figuras 1 e 2). As coletas de solo realizadas nos meses de junho e dezembro/91 e maio/92 apresentaram valores

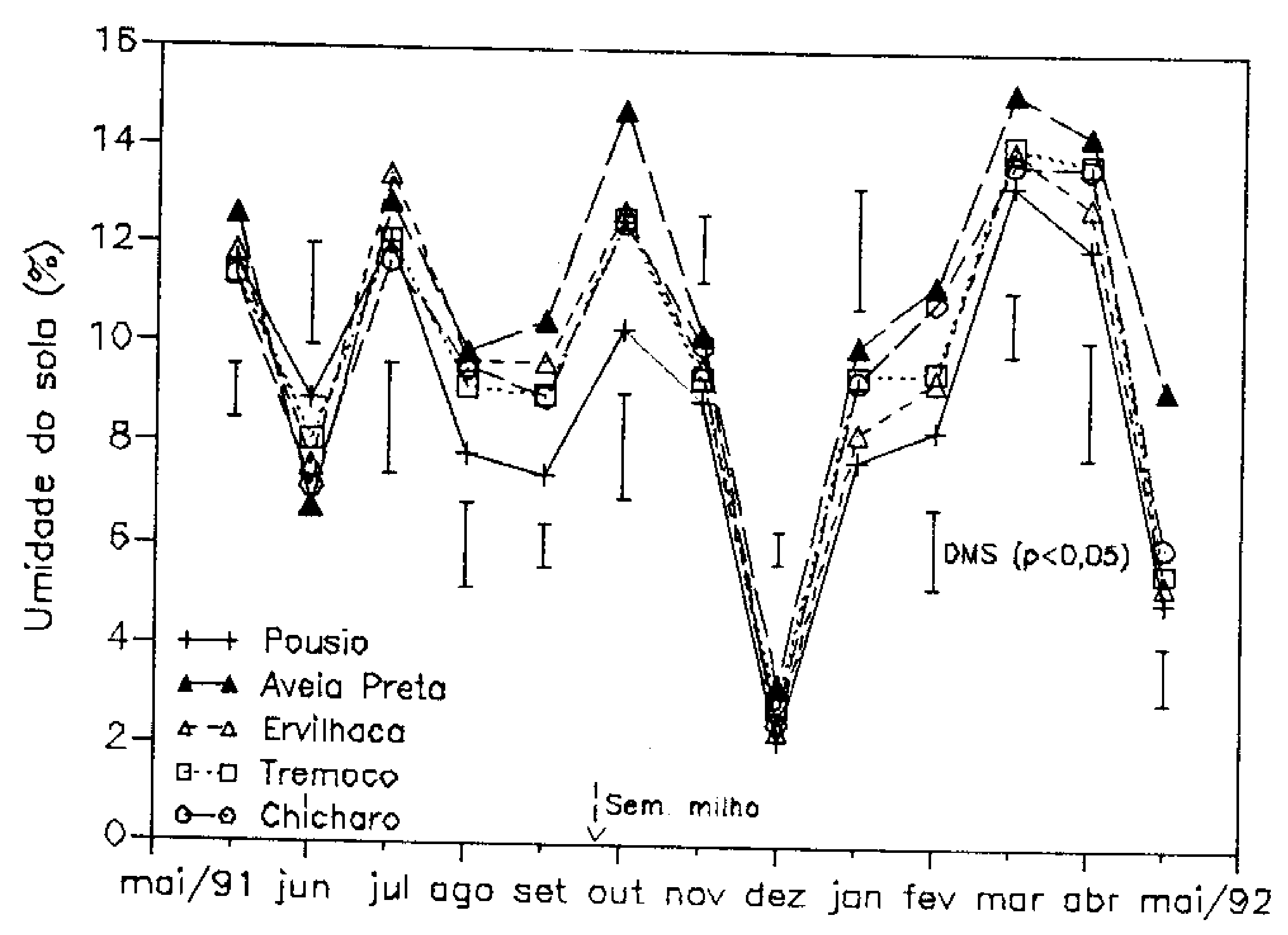

Figura 1 - Variação temporal da umidade do solo, na camada de 0 a $5 \mathrm{~cm}$, sob diferentes plantas de cobertura do solo na cultura do milho em plantio direto. Média de quatro repetições. Santa Maria, RS.

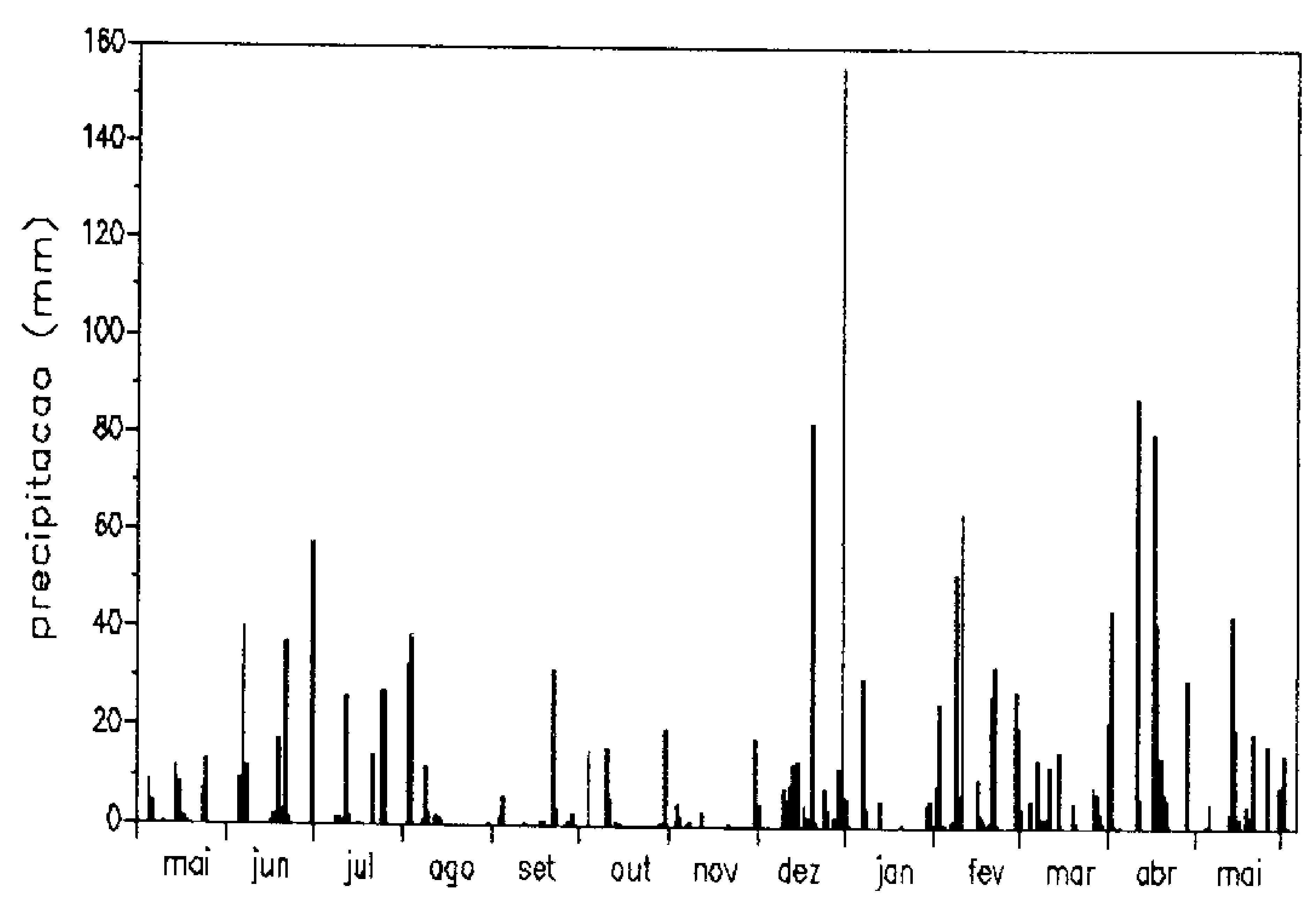

Figura 2 - Precipitação diária ocorrida no municipio de Santa Maria-RS, no período de maio de 1991 a maio de 1992. Dados da Estação Meteorológica da UFSM.

mais baixos de umidade do solo. As plantas de cobertura, de maneira geral, induziram maiores diferenças de umidade do solo, para os estados maiores de umidade do solo no momento da coleta. Os resultados demonstram que se fossem realizadas somente uma ou poucas coletas, a avaliação do efeito diferencial das plantas de cobertura na conservação da umidade do solo seria prejudicada.

$\mathrm{Na}$ maior parte do período, até agosto de 1991, a cobertura vegetal no pousio invernal, prática 
muito usada pelos agricultores da região, na qual a pouca proteção do solo é apenas feita por inços que crescem esporadicamente na área, estava abaixo dos $16 \%$, enquanto que, nos tratamentos aveia preta, evilhaca e chícharo, esta ficou acima dos 38\% (Figura 3). O tremoço azul apresentou menor cobertura do solo em relação às plantas de cobertura devido provavelmente ao seu hábito de crescimento ereto, enquanto as espécies leguminosas chícharo e envilhaca apresentam hábito prostrado (rastejante), que aumenta a cobertura do solo. A cobertura total do solo, devido a resíduos anteriores de planta mais a cobertura vegetal, considerando todo período analisado, foi superior nos tratamentos com aveia preta, chícharo e envilhaca (Figura 4). No entanto, após o manejo das plantas de cobertura, em 24 de setembro de 1991, o efeito da aveia preta, uma gramínea, foi superior as demais espécies, embora năo diferindo significativamente do chícharo. Estes dados sugerem a superioridade da gramínea em relação às leguminosas que apresentam menor taxa de crescimento inicial e menor relação carbono/nitrogênio. Esta menor relação $\mathrm{C} / \mathrm{N}$ leva à mais rápida decomposição dos resíduos de leguminosas por microrganismos. A diferença de

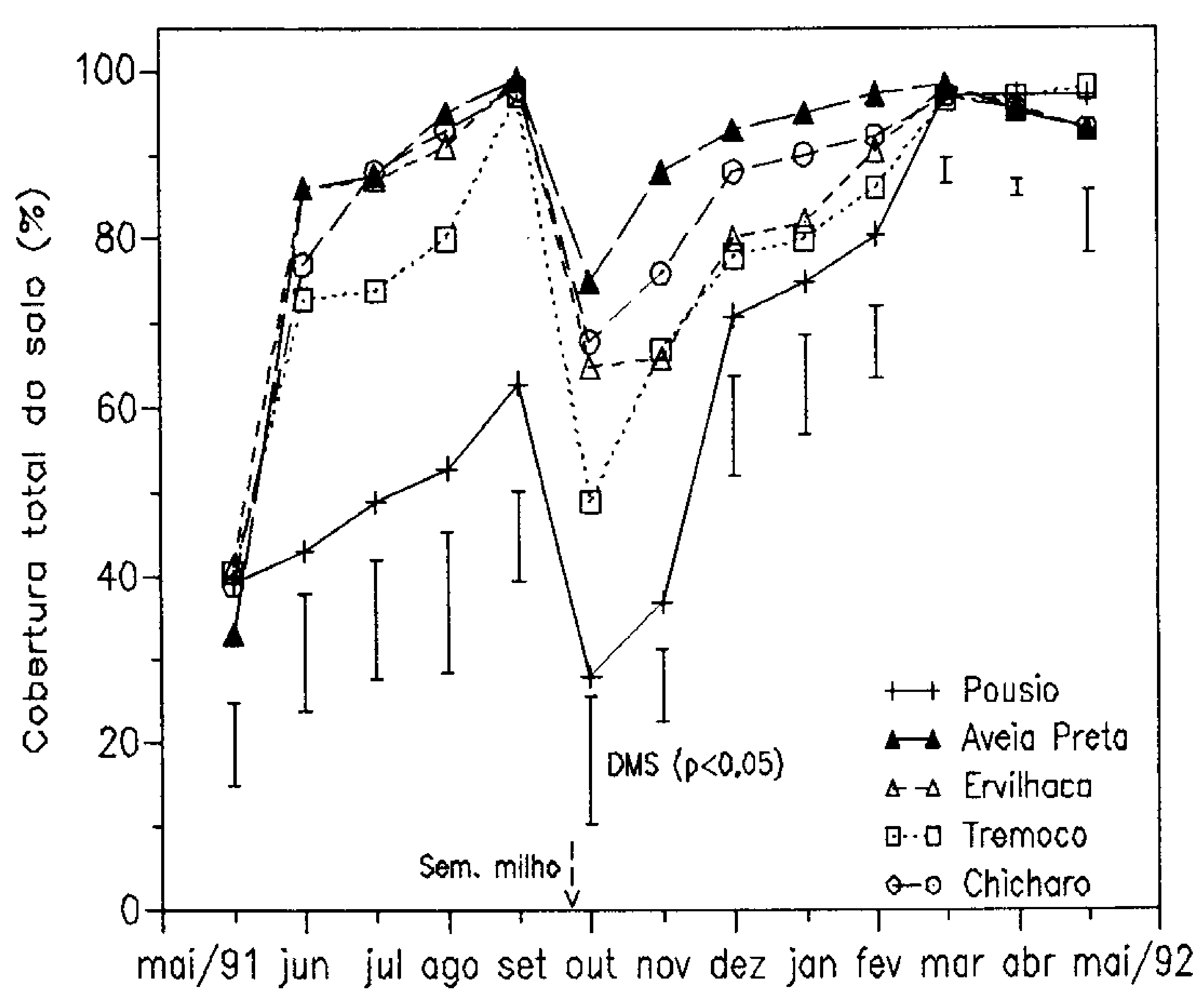

Figura 4 - Variação temporal da cobertura total do solo por plantas de inverno, pousio invernal e cultura do milho. Média de quatro repetições. Santa Maria, RS.

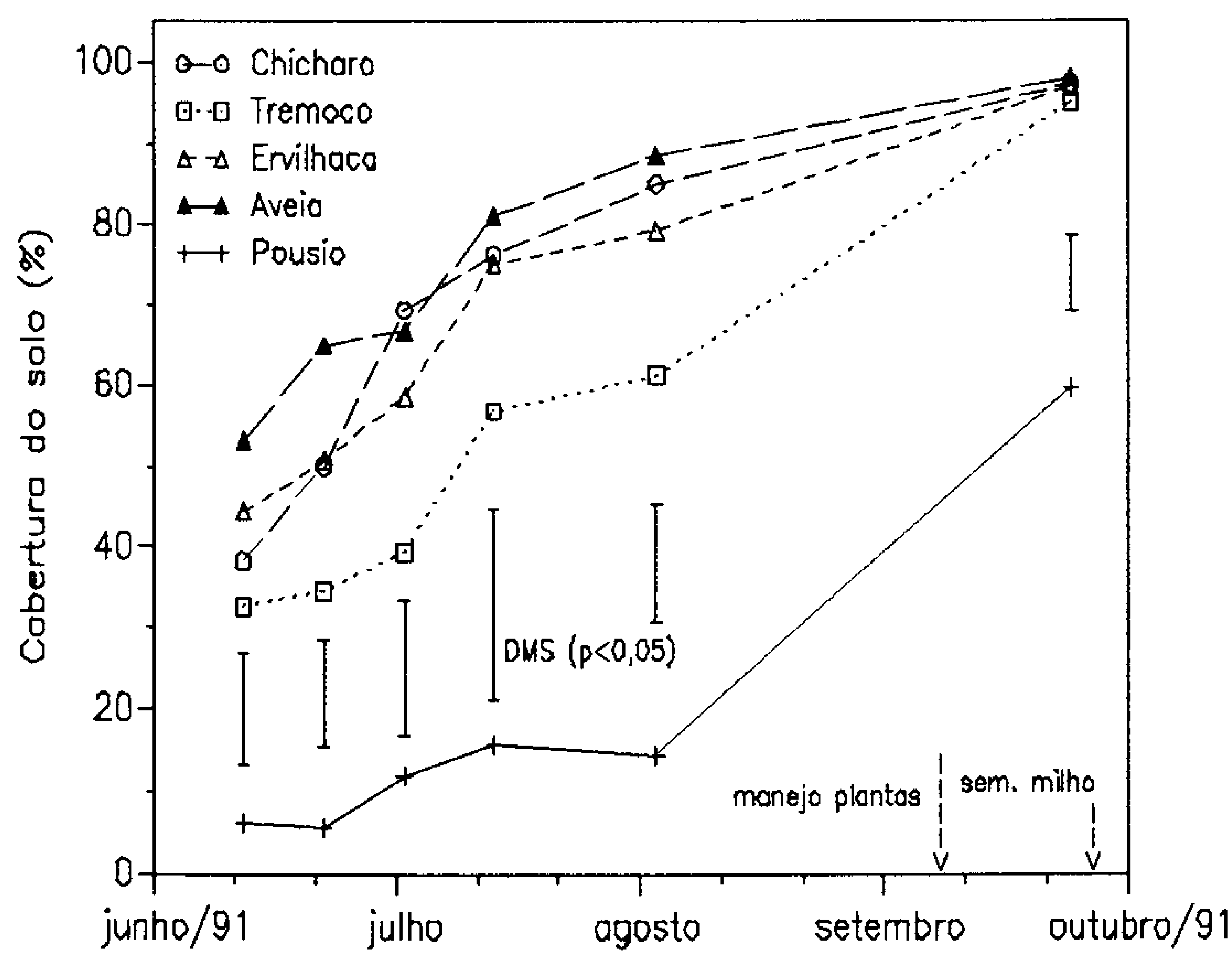

Figura 3 - Variação temporal da cobertura vegetal do solo por plantas de inverno e pousio invernal. Média de quatro repetiçóes. Santa Maria, RS. valores de cobertura do solo entre as Figuras $3 \mathrm{e}$ 4, para a mesma data, refere-se a percentagem devida à cobertura morta. Isto implica em maior importância da cobertura morta na manutenção da umidade do solo durante o período inicial de crescimento da planta de cobertura no inverno e da cultura do milho no verão.

O solo sob tratamento com a espécie aveia preta apresentou o maior valor de umidade durante praticamente todo o período de avaliação (Figura 1). As espécies leguminosas apresentaram resultados intermediários, com variação entre as mesmas ao longo do período. $O$ tratamento em pousio invernal, apresentou menor valor de umidade do solo ao longo de todo o período analisado.

Estes resultados estão diretamente ligados à taxa de cobertura total do solo ocorrida nos tratamentos estudados, sendo que a grande diferença é devida à presença ou ausência da cobertura viva e morta, dependente das espécies vegetais de inverno. Estes dados reforçam a grande importância da cobertura do solo sobre a conservação de umidade do solo, e também do efeito diferenciado das diferentes plantas de cobertura. 
BRAGAGNOLO e MIELNICZUK (1990), também encontraram efeito diferenciado das plantas de cobertura. Estes autores, avaliando oito seqüências de cultura em um Podzólico Vermelho-Escuro, destacaram $o$ guandu/guandu + milho $e$ lablabe/lablabe + milho, com maior eficiencia em manter a umidade do solo, os quais, após quatorze dias de estiagem, apresentaram respectivamente teor de água volumétrica no solo de 7,8 e 7,0\% superior ao tratamento pousio/milho, sendo que a cobertura do solo foi, respectivamente, de 69,79 e $11 \%$ na oportunidade da semeadura do milho.

A conservação da água no solo nem sempre está associada a cobertura do solo. DERPSCH et al. (1985) constataram que as perdas de água por evaporação foram evitadas ou reduzidas, através da cobertura da superfície com resíduos de Avena strigosa e de Lupinus albus. Entretanto, a cobertura da superfície com restevas de Raphanus sativus e Lathyrus sativus teve um efeito negativo na conservação de água em comparação com a parcela de pousio invernal sem resíduos de cultura. Segundo os autores, as diferenças no valor de umidade, no cultivo de soja e milho, sob os vários tipos de coberturas da superfície do solo, foram atribuídas em primeiro lugar ao grau de cobertura da superfície pelos resíduos de culturas, e em segundo lugar ao consumo da água do solo através das plantas cultivadas (soja e milho). Estes resultados vem ressaltar as observações feitas por MONEGAT (1991), de que os efeitos benéficos da cobertura vegetal variam de acordo com as condições de solo, clima, espécie e manejo utilizado.

\section{CONCLUSÕES}

O solo sob cultivo com aveia preta apresentou o maior valor de umidade durante praticamente todo o período estudado, indicando sua superior capacidade de conservar água, que está associado a maior eficiência de cobertura do solo. As leguminosas de inverno, chícharo, ervilhaca e tremoço foram eficientes na conservação de umidade, quando comparadas ao pousio do solo, que inclui somente ervas daninhas.

\section{REFERÊNCIAS BIBLIOGRÁFICAS}

BAVER, L.D., GARDNER, W.H., GARDNER, W.R. Fisica de Suelos. 1. ed. México: U.T.E.H.A, 1973. cap. 7: Régimen térmico de los suelos: p. 267-298. 1973.

BLEVINS, R.L., COOK, D., PHILLIPS, S.H., et al. Influence of no llage on soil moisture. Agronomy Journal, Madison, v. 63, p. 593-596, 1973.

BRADY, N.C. Natureza e propriedades dos solos. 7. ed. Rio de Janeiro: Freitas Bastos, 1989. cap. 15: Perdas de umidade do st e suas normas: p. 571-612.

BRAGAGNOLO, N., MIELNICZUK, J. Cobertura do solo por resíduos de oito seqüencias de culturas e seu relacionamento com a temperatura e umidade do solo, germinação e crescimento inicial do milho. Revista Brasileira de Ciéncia do Solo, Campinas, $v$ 14, p. $91-98,1990$.

BRASIL. Ministério da Agricultura. Levantamento de reconhecimento dos solos do Estado do Rio Grande do Sul. Recife: Departamento Nacional de Pesquisa Agropecuária, Divisão de Pesquisa Pedológica, 1973. 431 p. Boletim Técnico, 30.

DERPSCH, R., SIDIRAS, N., HEINZMANN, F.X. Manejo do solo com coberturas verdes de inverno. Pesq Agropec Bras, Brasília, v. 20 , n. 7, p. 761-773, 1985 .

KAY, B.D. Rates of change of soil structure under different cropping systems. Advances in Soil Sciences. v. 12, p. 1-41, 1990.

MENDES, E.V. Métodos de preparo do solo: influência sobre alguns propriedades químicas e fisicas. Santa Maria - RS. 93 p. Tese (Mestrado em Agronomia) - Curso de Pós-Graduação em Agronomia, Universidade Federal de Santa Maria, 1982.

MONEGAT, C. Plantas de cobertura do solo: caracteristicas e manejo em pequenas propriedades. Chapeco, Ed. do Autor, 1991. $336 \mathrm{p}$.

MUNAWAR, A., BLEVINS, R.L., FRYE, W.W., et al. Tillage and cover crop management for soil water conservation. Agronomy Jama, Madison, v. 82, p. 773-777, 1990.

PRASAD, R., POWER, J.F. Crop residue management. Advances in Soil Science, New York, v. 15, p. 205-251, 1991.

SPEDDING, C.R.W., LARGE, R.V. A point quadrat method for the description of pasture in terms of height and density. Journal of the Bristish Grassland Society, Aberystwth, v. 12, n. 4, p. 229-234, 1957. 